\title{
Lewis Base Catalyzed Asymmetric Selenoetherification
}
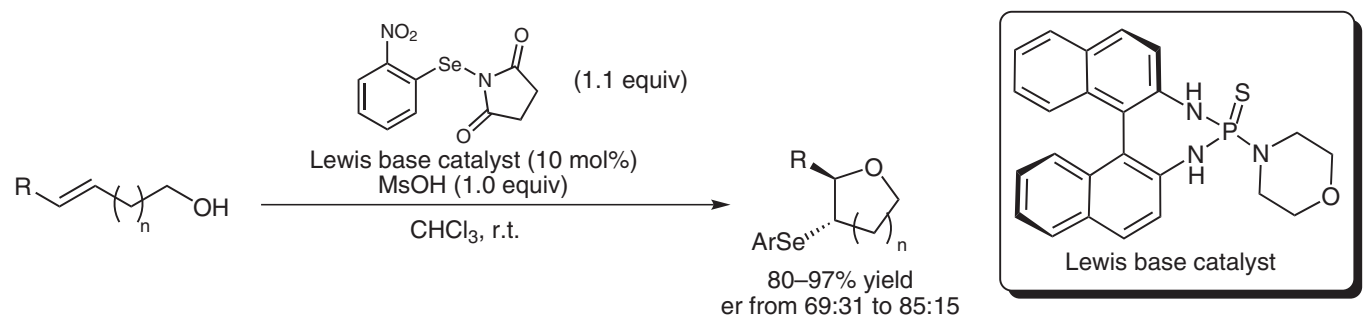

Proposed mechanism:
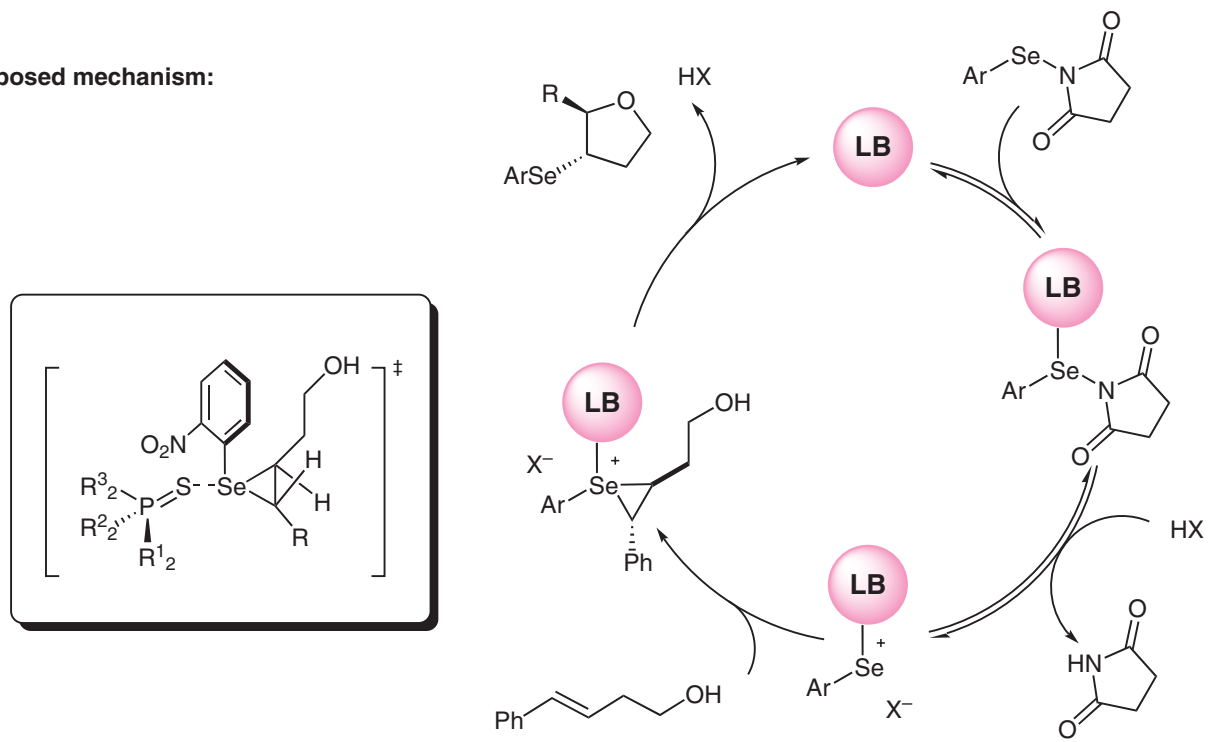

Significance: Selenofunctionalizations represent an important class of reactions available to the synthetic chemist due to the versatility of the products. The synthesis of enantiomerically enriched products containing selenium has relied on the use of chiral selenylating agents or substrate control, which is not ideal by today's standards of efficiency and atom economy. The authors report the first Lewis base catalyzed asymmetric selenofunctionalization of unactivated olefins and have carried out detailed mechanistic studies, which shed light on the various elements of the catalytic cycle and pave the way for future reaction design.

SYNFACTS Contributors: Mark Lautens, David A. Candito Synfacts 2011, 1, 0047-0047 Published online: 21.12.2010 DoI: 10.1055/s-0030-1259178; Reg-No.: L16110SF
Comment: Key to the success of this transformation was the identification and suppression of racemization pathways available to the key seliniranium ion intermediate. Two pathways were identified; nucleophilic attack of the pendant nucleophile on the selenium rather than carbon, and exchange of selenium cations between olefins. Each process would lead to an achiral background reaction compromising the enantioselectivity. The authors overcame these challenges by judicious choice of the aryl group on the selenylating agent. The authors provide compelling evidence and explanations on various aspects of the proposed catalytic cycle and have a good foundation for further reaction design.
Metal-Catalyzed Asymmetric Synthesis and Stereoselective

Reactions

Key words

Lewis base catalysis

selenofunctionalization

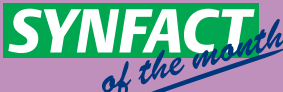

